\title{
Tunnelling to 50: an exploratory medical memoir
}

\section{David S. Goldbloom}

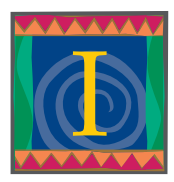

$t$ began in the summer of 2003. I went to see my internist about my inability to fully flex my right knee during squash matches. His secretary ushered me into his examining room and told me to undress and await his appearance. Stripped to my boxers, I heard my cell phone ringing. It was my assistant with an urgent question about our hospital. I explained that it was not the best time for me to talk as I was standing in my doctor's examining room in my underwear. A compassionate soul, she asked in a worried tone if I was alright. I was telling her that I was here for an estimate on that new penis reduction procedure when my internist entered the room. This may have been the last funny moment in the medical odyssey on which I was about to embark.

My internist examined my knee closely for several minutes and concluded, "there's something wrong with your knee." I chided him for the technical gobbledegook and accepted his referral to an orthopedic surgeon, as well as an appointment for both an ultrasound and an MRI of the affected joint. As I moved toward the door, he mentioned "by the way, since you're almost 50, you should have a colonoscopy." I'm pretty sure that's what he said, or maybe it was that I should take needle-nose pliers and rip out my finger nails. The visceral response was the same.

A scant 3 months later, my wife escorted me to the Upper Canada Lower Bowel Clinic (I am planning a gastroduodenoscopy in Montreal at the Lower Canada Upper Bowel Clinic). I was still recovering from the bowel prep the day before, a procedure akin to compressing 6 weeks of the Atkins diet into 24 hours with the help of intercontinental ballistic purgatives. The gastroenterologist, wielding the endoscope like Zorro, inserted an intravenous line and sent me off to la-la land with meperidine and midazolam. I remember offering to lie on my left side and think of England as he initiated the procedure. From that point on, I was in a hallucinogenic orbit, rehearsing my unscheduled audition for the role of Max Bialystock in the Toronto production of The Producers. I was shaken from my reverie by the doctor's announcement "I'm at your cecum" and wondered if, with his flexible endoscope, he was going to turn around or just back up on his scenic tour of the tunnel at the end of the light. The rush of the analgesia and the floating calm of the intravenous anxiolytic were extraordinary and seductive; the first of several medical phobias was conquered! He said I should have another colonoscopy in 10 years. I'm not sure I want to wait that long.

Several weeks later, I found myself lying on an operating room table about to have another scope inserted in a place where Nature never intended. The MRI of my knee had revealed a complex tear of the posterior horn of the right medial meniscus - one that could not be fixed by either time or Crazy Glue. Accordingly, I was knocked out with propofol, a short-acting general anesthetic from which one wakes up quickly. In a little less than an hour, the surgeon cut out the errant piece of tissue through 2 tiny incisions on either side of my knee and presented me with photographic before-and-after evidence of his work. Not only did I survive my first general anesthetic, I walked out of the hospital only an hour after coming to.

Most recently, I had yet another probe inserted. This time, it was not a joint or a viscus but rather the very root of my own medical terror - a molar root. (My sister has explained to me that my fear of things dental has its origins not in our early childhood encounters with our dentist himself but rather the maternal figure who accompanied us to those appointments. My mother, who had likely not experienced the zenith of advances in dental pain control as a child, was the Typhoid Mary for the airborne spread of sheer terror in the dentist's waiting room.) For the past couple of months, I had been experiencing some pain in a right upper molar. I finally succumbed and visited my dentist. He concluded blandly that I needed a root canal (I'm pretty sure it was my dentist who said that, although I

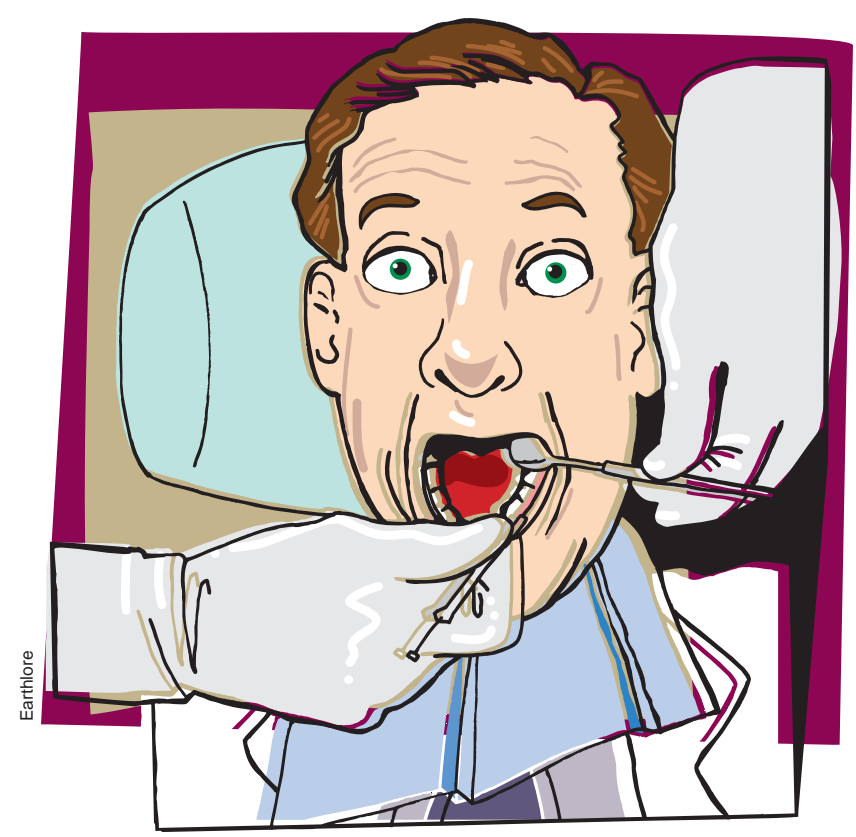


couldn't be sure since my eyes were squeezed shut to avoid any accidental visual contact with a dental instrument). I said I would certainly consider that possibility, and he booked me for a procedure with an endodontist that afternoon. As I started to lose feeling from the knees down, I scrolled through my Palm, desperately hoping to find a scheduling conflict. Great! A committee meeting. But it occurred to me that the root canal might be a better option, so I dutifully showed up. In the exchange of pleasantries, I casually mentioned that I had a mild fear of pain, with a possible focus on dental pain. The endodontist was reassuring and managed to sneak the needle past my wide-eyed visual field and froze my mouth quickly (by then I had lost almost all sensation below my shoulders). For 90 minutes, he reamed the roots painlessly, although not without physical sensation. Once again my experience was limited by the total darkness into which my scrunched eyelids plunged me, but it felt as if he placed my lower jaw into the grip of the electric paint can shaker at the hardware store and then pressed the start button. When all was done, I left his office with 1200 new Aeroplan points and, most important, the realization that I survived the procedure without pain; teeth cleaning is more uncomfortable (perhaps because of the inevitable accompanying lecture).

I hope that this medical peregrination is now over for a while. I am relieved to be beyond those things I have dreaded, although I suspect that when it comes to medical procedures, it is still better to give than to receive.

David Goldbloom is Senior Medical Advisor, Education and Public Affairs, Centre for Addiction and Mental Health, and Professor of Psychiatry, University of Toronto, Toronto, Ont.

\section{House calls}

\section{Peter Richard Elphick}

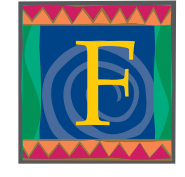

orty years ago, it usually began this way: "Ask the Doctor to call. I think Mother has a chill."

"He'll be there as soon as he can."

The doctor would bring a bag with a stethoscope, and perhaps a patellar hammer to check her reflexes. A prescription for a tonic, written in abbreviated Latin, would complete the required reassurance. Mist. Strych. et Fer dr.11 QID. Mitte oz.xxx. The patient's chill would dissipate after only a sneak peek at the missive intended for the chemist.

The tonic? A mixture of iron, laced with a small amount of strychnine to add a little piquance to the already bitter flavour, in a 30-ounce bottle with instructions to take 2 drams 4 times per day. The symbols for drams and ounces are not reproducible on a typewriter, but the former had an appearance of a number 3 with a double flat top and an elongated tail, while the latter was the same with only 1 hat. The flourish added to the hats and tails increased their mystique, while the pharmacist's ability to interpret the remainder ensured his place in the inner circle of healers. The mixture was bile green, which matched its taste, and had no therapeutic effect. Most people got better anyway.

As I remember it, the request for house calls always occurred at night, during meals, a shower or when the biological immediacy of matters at hand would make even Florence Nightingale reluctant to respond.

I have to admit, however, that those were interesting times. There was the occasion when a snowfall had buried $\ddot{\vec{*}}$ the car, the doors frozen shut; or the night a bear was $\AA$ perched on the bonnet, for all the world like an overgrown cat; or the time one of his ursine friends was exploring the garbage in the carport.

"Tell him to knock and walk right in. I'm upstairs on the left." Today, it sounds like B-movie dialogue. But that was how it worked.

Once, I got the wrong house; another time, I had to climb through an upstairs window to enter. It helps to be youthful.

One 1964 night in Plymouth, England, the voice on the other end of the phone provided the following directions: "It's down by the docks, m'dear. You know, where the

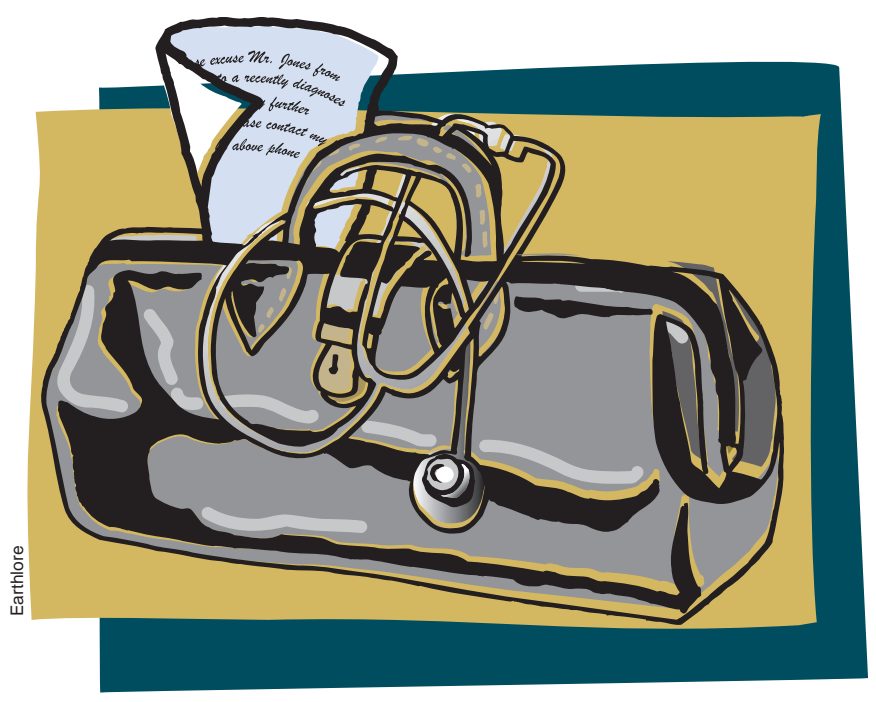

